tity of "betterness" or "worseness" in an ingot being added to or subtracted from the weight of it, gives the quantity of standard metal containes in it," and that therefore the "betterness" or "worseness" affords a ready means of determining the amount of copper or gold required to standardise the whole. Further, if a number of ingots of varying weights and fineness have to be dealt with, a similar result will be arrived at by taking the algebraical sum of the several products of their weights and "betterness" or "worseness." These advantages, however, apply to individual calculations, and become unimportant when standarding tables adapted to the decimal system are available. ${ }^{1}$

In a letter to Mr. Fremantle, Prof. Roberts advocated the abolition of this old system of carats and grains and the adoption of the decimal system. This has accordingly been carried into effect. Gold of the value of two millions sterling has recently been imported for coinage, and the simplicity and accuracy of the new system has been abundantly demonstrated.

The facts above stated may seem comparatively unimportant in themselves, but the Mint may at any time be called upon to coin (as was the case in 1872) fifteen millions sterling of gold in a single year, and extreme care has to be taken to insure accuracy in the standard fineness of the metal. It is curious that the old system described above should not have given place before now to that which has long been adopted in other countries.

\section{THE POISONOUS LIZARD"}

THE Gila Lizard of Arizona and Sonora has anterior, deciduous, grooved teeth, which communicate by ducts with large glands within the angle of th. Jwer jaw -an apparatus so strongly resembling the poison-fangs of serpents as to suggest that this lizard has venomous properties. It is said by the natives of Mexico to be very poisonous, but others again have declared that it is perfectly harmless. One specimen sent to Sir John Lubbock killed a frog in a few minutes and a guinea-pig in three minutes.

The conflicting statements are probably due to the fact that the teeth are very small and easily removed. Some specimens of the creature reach the length of three feet. As experiments made by allowing the lizard to bite animals are untrustworthy on account of the uncertainty of getting the poison equally introduced into the tissues at every bite, Doctors Weir Mitchell and Reichert collected the saliva so as to be able to inject it in known quantities. The saliva was obtained by making the animal bite on a saucer-edge. It dropped in small quantities from the lower jaw, and had a faint and not unplensant aromatic odour. It was distinctly alkaline, in contrast to serpent venoms, which are all alike acid. Four and a half minims of it diluted with half a cubic centimetre of water and injected into the breast of a large pigeon caused the bird to walk unsteadily after three minutes. At the same time the respiration became rapid and short, and at the fifth minute feeble. At the sixth minute the bird fell in convulsions with dilated pupils, and was dead before the end of the seventh minute. There was not the least trace of any local effect of the poison, as there would have been in the case of crotalus venom. The muscles and nerves were perfectly sensitive to stimulation mechanically or by weak induced currents. The heart was arrested in complete diastole, and was full of firm, black clots. The intestines looked congested. In another experiment it was found that the poison gradually

I Tables on the system above described were first published in the year 1651, having been prepared by Mr. Reyn lds, Assay Master at the Mint in the Tower A second edition was afterwards issued with corrections and additions in $\mathrm{r} 677$.

2 "A Partial" Study of the Poison of Heloderma suspectum (Cope), the Gila Monster." By Dr. S. Weir Mitchell and Dr. E. T. Reichert of
Philadelphia. lowered the arterial tension and rendered the pulse irregular. Its action on the pulse is not due to any effect upon the pneumogastric nerves, as it is just the same when these nerves are cut. When applied to the heart of a frog it arrests its pulsation; in diastole, and the organ afterwards contracts slowly-possibly in rapid rigor mortis. The cardiac muscle loses its irritability to stimuli at the time it ceases to beat. The other muscles and nerves respond reatily to irritants, but the spinal cord has its power annihilated abruptly and refuses to respond to the most powerful electrical currents.

The authors conclude that "this interesting and virulent heart poison contrasts strongly with the venoms of serpents, since they give rise to local hemorrhages, and cause death chiefly through failure of the respiration and not by the heart, unless given in overwhelming doses. They lower muscle and nerve reactions, especially those of the respiratory apparatu;, but do not as a rule cause extreme and abrupt loss of spinal power. Finally, they give rise to a wide range of secondary pathological appearances which are absent from Heloderma poisoning."

This distinction between the action of the poison of Heloderma and serpent venom is correct as far as regards the poison of the rattlesnake and perhaps also the Crotalidæe generally, but the distinction is by no means marked between the poison of Heloderma and the venom of the cobra. This venom was found by Sir Joseph Fayrer and Dr. Lauder Brunton to have but a slight local action as contrasted with that of the rattlesnake or of the daboia, and to produce no local hernorrbage. The effect of cobra poison on birds also is very much the same as that of the Heloderma; and in the experiments given in this preliminary paper, the effect of the Heloderma poison on the heart of the frog is very much like that of cobra poison, the failure of action with subsequent and gradually increasing contraction being almost precisely the same. ${ }^{1}$

In Brunton and Fayrer's experiments on cobra poison, the fall of blood-pressure was less marked, but it still occurred. Paralysis of the spinal cord also is produced by cobra poison, and the experiments in this preliminary paper are too few to enable us to decide whether the paralysing effect is greater from the poison of Heloderma than from cobra venom. We shall look with much interest to the further study of the venom of this curious animal, which the authors intend to make on the arrival of the fresh specimens which they are about to receive.

\section{ON THE CONDENSATION OF VAPOUR FROM THE FUMAROLES OF. THE SOLFATARA OF POZZUOLI}

THE fumaroles of the Solfatara of Pozzuoli, and especially the larger fumarole known as the Bocia della Solfatara, give a striking illustration of the action of smoke in causing the condensation of aqueous vapour in the manner demonstrated by the experiments of Coulier, and more especially by those of Dr. Aitken.

Persons who have visited the Solfatara will remember that one of the feats by which the ciceroni of the place try to excite the wonderment of visitors is to light some paper or a few dry branches, and put the flaming body before or inside the mouth of the principal fumarole, augmenting thus very greatly the volumes of cloudy vapour escaping from the fissure. This phenomenon can be observed in all volcanic fumaroles. A flame is not indispensable, the condensation of the vapour being also produced by the mere smouldering of tinder.

Prof. Piria first tried to explain the phenomenon. $\mathrm{He}$ thought that small quantities of sulphuretted hydrogen issued from the soil together with the aqueous vapour:

$x$ Brunton and Fayrer on the Poison of Indian Venomous Snakes (Roy. Soc. Proceedings, January 22, 18/4, p. I26). 